\title{
RECYCLING OF BITUMINOUS PAVEMENTS
}

\author{
JAMES L. McKinney \\ Graduate Research Instructor \\ Purdue University
}

\section{INTRODUCTION}

The major material utilized in the construction of the roads, streets and highways of this country is asphalt. Of the nation's 3.84 million miles of roads, 1.86 million are paved, hard-surfaced structures. 1.74 million or $94 \%$ of these paved roads are constructed of asphalt (Fig. 1). Likewise, within the state of Indiana, $83 \%$ or about 9300 miles of the 11,200 miles under the jurisdiction of Indiana State Highway Commission, are constructed with asphalt.

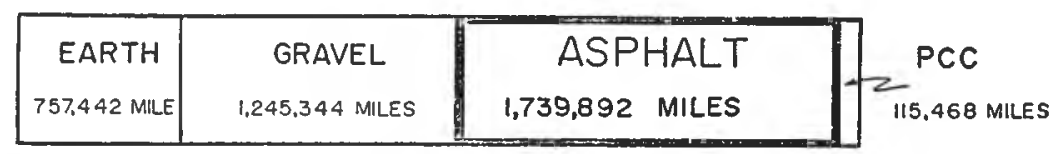

TOTAL MILEAGE $-3,838,146$

Figure 1. Total Existing Length of Roads and Streets, USA, by Surface Type (The Asphalt Institute).

One of the tasks assigned to transportation agencies throughout the country is the maintenance and rehabilitation of the highways under their jurisdiction, the majority of which are asphalt roads. This has always been a major task, but lately it has escalated into one of the major problems facing these agencies today.

TRIP, The Road Infirmation Program, estimates that 767,000 miles of the 1.86 million miles of paved roads are seriously deteriorated. In otherwords, $42 \%$ of the country's paved roads are in need of resurfacing and reconstruction. Furthermore, within the state of Indiana, 18,300 miles of the nearly 92,000 total miles of roads, streets and highways are rated poor.

Compounding the problem is the increased costs that these agencies are faced with. When compared to 1973, the following indicators of highway costs show these increases (Fig. 2, 3, 4, 5): 


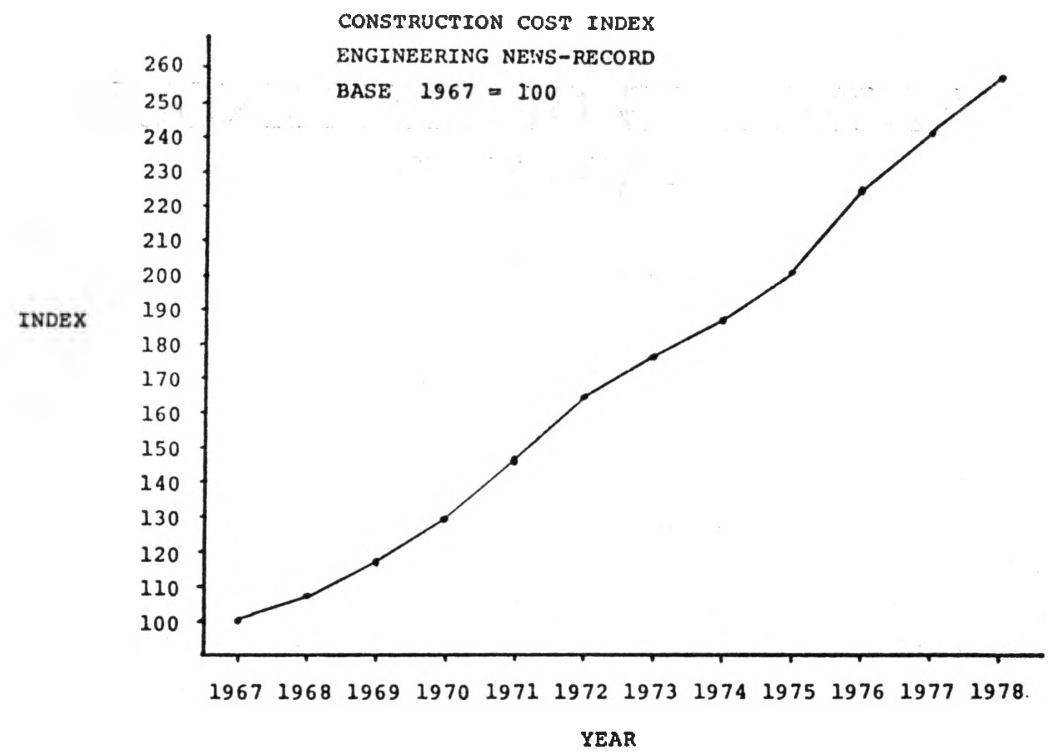

Figure 2. Engineering News Record Construction Cost Index (ENR).

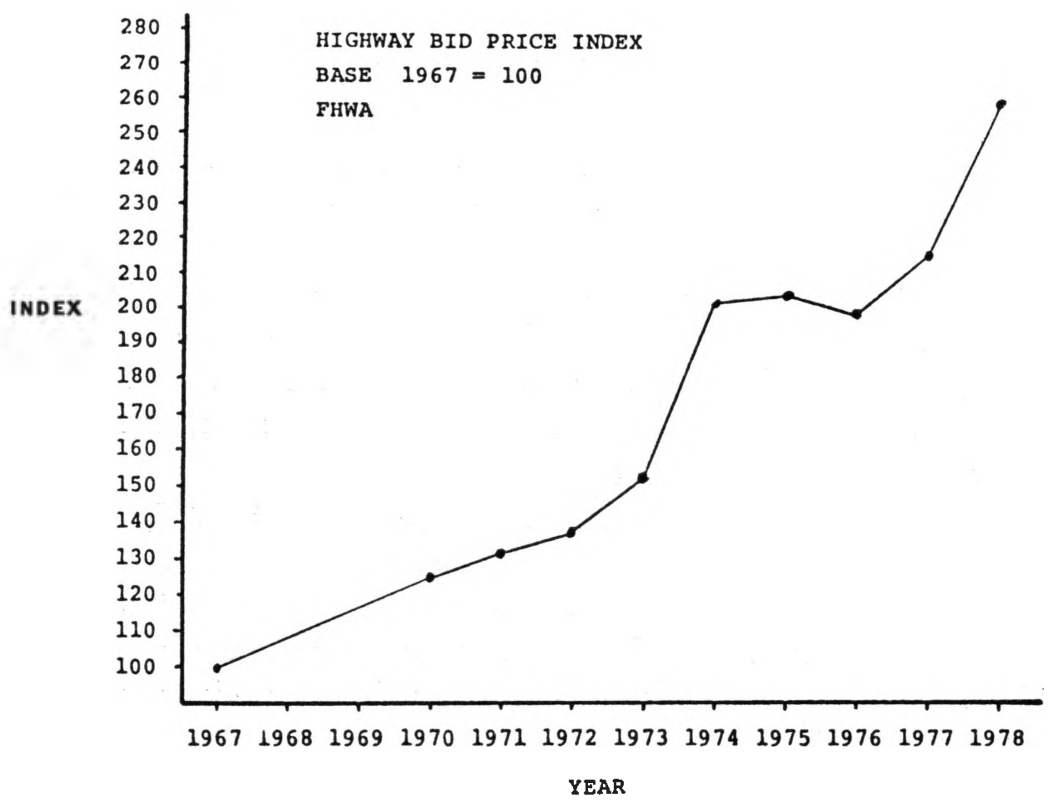

Figure 3. Combined Highway Bid Price Index (FHWA). 


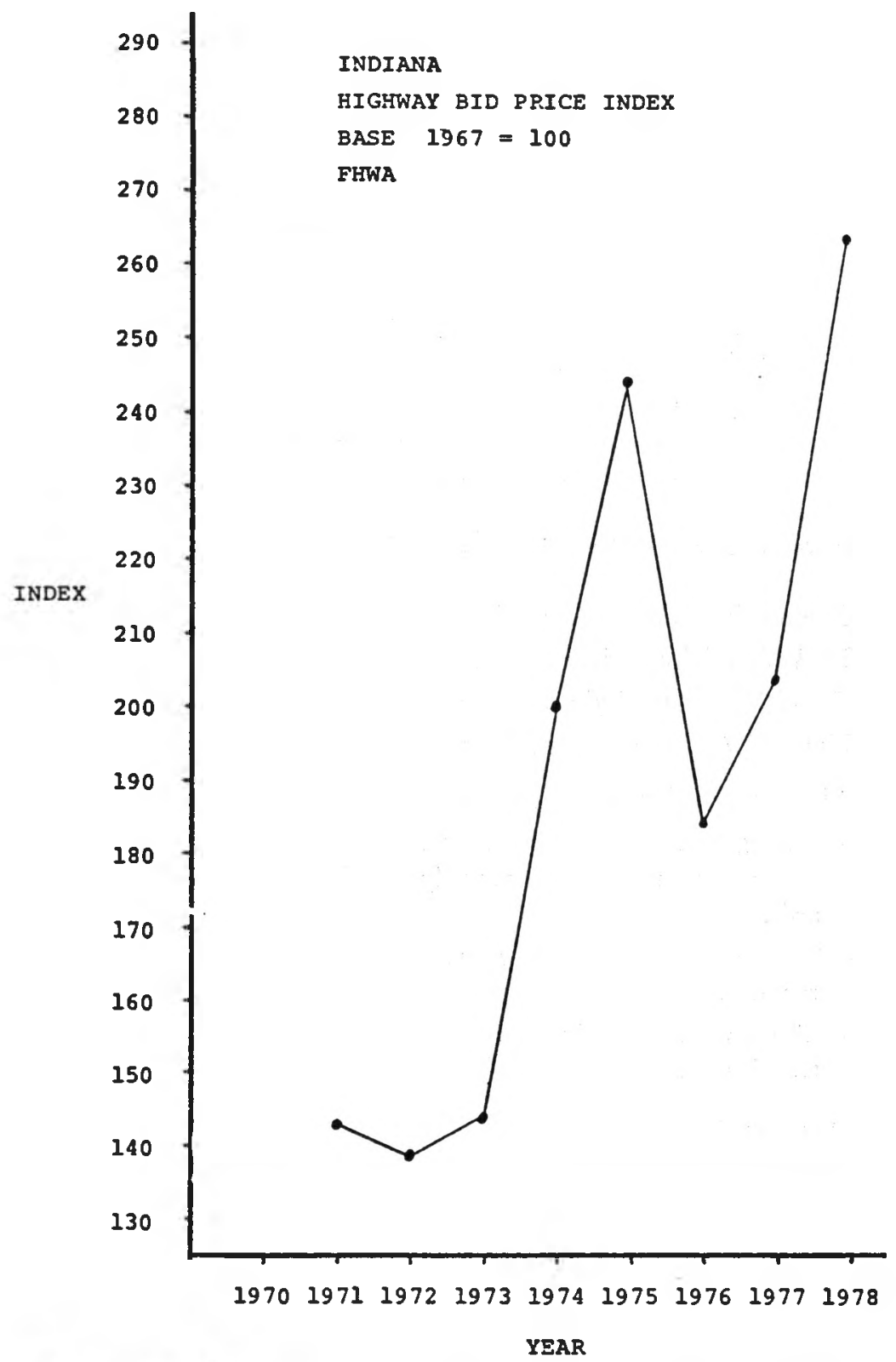

Figure 4. Indiana Combined Highway Bid Price Index (FHWA). 


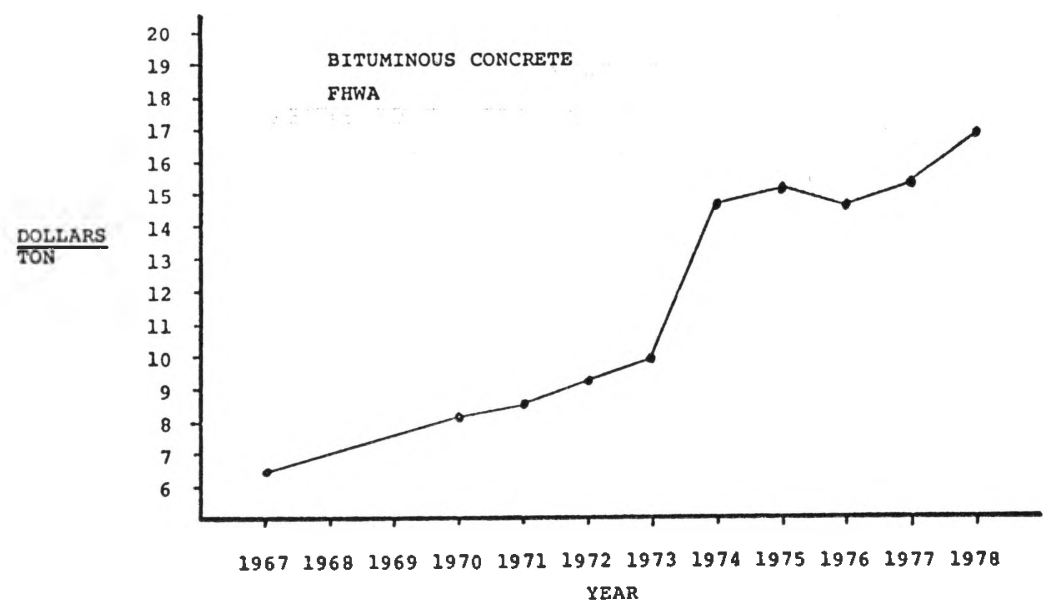

Figure 5. Material Cost, Per Ton, of Bituminous Concrete (FHWA).

Engineering News Record Construction Cost Index up 52\%

FHWA Highway Bid Price Index

up $77 \%$

FHWA Indiana Highway Bid Price Index

up $82 \%$

National Average Price of Bituminous Concrete

up $71 \%$

Also contributing to the problem are the following related factors:

-Slow growth or leveling off of gasoline tax revenues due to conservation measures and federally mandated vehicle mileage standards.

- The reallocation of maintenance funds to other uses, such as snow removal.

- The diversion of highway funds to other programs such as mass transit uses.

\section{RECYCLING}

One concept that accounts for the wide use of asphalt and tries to deal with these maintenance problems is the recycling or reuse of asphalt pavements. Traditionally, the methods used to maintain asphalt pavements have run the gamut of alternatives from doing nothing, to crack sealing, to surface treatments, to thin and thick overlays, to removal and reconstruction. Now recycling has been shown to be a viable maintenance alternative. Recycling recognizes the inherent value of the pavement and reuses it in a new form.

Recycling is not a new technique. One of the earliest recorded recycling efforts was that of the Warren Brothers, a Massachusetts con- 
tractor who experimented with recycling of sheet asphalt pavements in 1915. Recycling of asphalt pavement was also tried in Singapore in the 1920's. Later, recycling took the form of "stage construction," a concept that embodied the reuse or "recycling" of the existing pavement. But with the emphasis on new construction, particularly coinciding with the development of the interstate highway system, recycling was relegated to the background. However, with the oil embargo of 1973 and the resultant sharp rise in all construction costs, recycling once again became a viable rehabilitation alternative. Since 1974 recycling has grown from 5,000 tons a year to about six million tons in 1978. The Federal Highway Administration estimates that by 1980, 50 million tons of asphalt pavements will be recycled. Furthermore, FHWA estimates that by 1982 one-third of all asphalt paving will be recycled asphalt.

\section{Reasons for Recycling}

Why recycle? The answer to this question can be found in three major areas: economics, energy and environment.

\section{Economics}

From an economics point of view, recycling shows promise of financial savings over new, virgin construction. With oil prices and the associated asphalt prices increasing, FHWA estimates that recycling can save $25 \%$ or more on the cost of constructing bituminous pavements, as compared to nonrecycled costs. Looking at the materials alone, reclaiming existing asphalt pavements can mean a substantial savings in raw material costs. The 50 million tons of asphalt concrete that FHWA estimates will be recycled in 1980 is currently worth $\$ 395$ million (Fig. $6)$.

\section{VALUE OF 50 MILLION TONS OF RECYCLED ASPHALT}

\section{MILLION GALLONS ASPHALT \\ 30 MILLION TONS AGGREGATE \\ 17 MILLION TONS OF SAND}

$\$ 250$ MILLION $\$ 105$ MILLIOH

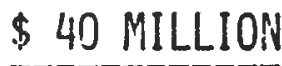

\section{TOTAL VALUE $\$ 395$ MILLION}

Figure 6. The In-Place Material Value of 50 Million Tons of Asphalt Concrete (FHWA 1978). 


\section{Energy}

From an energy standpoint recycling can mean a savings in energy consumption over new construction. This is particularly evident in the area of manufacturing the bituminous concrete. Each ton of bituminous concrete put into place represents about 500,000 Btu's (Fig. 7). This energy demand of $500,000 \mathrm{Btu}$ is due to the manufacturing and transportation of the raw materials, mixing these materials together, and transportation and putting the mix into place. Therefore, the 50 million tons of material to be recycled in 1980 represents an equivalent amount of gasoline of 200 million gallons. If $50 \%$ of this energy can be saved through recycling an equivalent savings of 100 million gallons of gasoline can be realized.

\section{Environment}

Environmentally, recycling typifies the positive aspects of reusing a finite resource. Recycling eliminates the problem of trying to dispose of discarded materials. In some areas of this country, disposal charges

TYPICAL ENERGY CONSUMPTION-HOT MIX ASPHALT

\section{RAW MATERIALS}

$\begin{array}{llcr} & & \text { Miles } & \text { Btu/ton } \\ \text { Asphalt - } & \text { Manufacture \& Transport } & 25 & 840,000 \\ \text { Crushed Stone - Manufacture \& Transport } & 10 & 155,000 \\ \text { Sand - } & \text { Manufacture \& Transport } & 10 & 100,000\end{array}$

MIX COMPOSITION

\begin{tabular}{rrrrrr} 
& & Btu/ton & & Btu/ton \\
Asphalt - & $6 \%$ & $@$ & 840,000 & & 50,000 \\
Crushed Stone $-60 \%$ & $@$ & 155,000 & $=$ & 93,000 & \\
Sand - $34 \%$ & $@$ & 100,000 & $=$ & 34,000 & \\
\multicolumn{2}{r}{ Total for mix } & & & & $\frac{177,000}{177,000}$
\end{tabular}

PLANT OPERATIONS

Dry aggregate -

Heat asphalt -

Misc. operations -

Total for plant

$$
\begin{gathered}
\text { Btu/ton } \\
126,000 \\
97,000 \\
20,000 \\
\hline 243,000
\end{gathered}
$$

243,000

HAUL \& PLACE

$$
\begin{aligned}
& \text { Haul - } 71 / 2 \text { miles } \\
& \text { Spread \& compact }- \\
& \text { Total for haul \& place } \\
& \text { Total for mix in place }
\end{aligned}
$$$$
\text { Btu/ton }
$$$$
64,000
$$$$
17,000
$$$$
\overline{81,000}
$$

501,000

Figure 7. The Amount of Energy Required to Produce and Place One Ton of Hot Mix (The Asphalt Institute). 
of up to $\$ 18$ per ton are being assessed to dump all discarded pavement materials. Recycling can also aid in conserving natural resources. In some parts of the nation problems exist in obtaining quality aggregates. Recycling can help alleviate this problem. For every 1000 tons of bituminous concrete reclaimed, 285 barrels of asphalt can be recovered, as well as 950 tons of well-graded, quality aggregate.

\section{Other}

There are other benefits to be realized from recycling. One is in the area of roadway geometry, particularly in urban areas. Vertical clearances that would otherwise pose a problem when a pavement is overlayed can be kept constant. Pavement cross slopes can be maintained and excessive roadway crowns be avoided. Curb reveal and associated drainage can also be maintained. Reconstructing utility structures to meet new overlay elevations can be eliminated.

Another benefit from recycling is the tendency to produce a better product. Weak spots and previous "mistakes" can be identified and corrected. Preliminary test results seem to indicate that the recycled bituminous mix is a better product than a new mix when low temperature cracking and aggregate stripping characteristics are considered.

\section{HOW TO RECYCLE}

Similar to the federal $3 R$ program: Resurface, restore and rehabilitate, recycling can be called the $3 R E$ program: REmove, REmix, REpave. Basically recycling can be classified into three major categories:

1. Surface recycling

2. Central plant recycling

3. In-place recycling

\section{SURFACE RECYCLING}

Surface recycling deals with the rehabilitation of the upper layer of a pavement. This form of recycling is particularly good for pavements that exhibit surface distress problems that are not of a structural origin. This recycling method is also good for urban areas where pavement geometry, utility structures and vertical control must be maintained.

Surface recycling can be broken into two major categories: Hot process-where the surface is initially heated prior to recycling; and Cold process-where the surface is recycled without the addition of thermal energy.

\section{Hot Process}

Heater-Planer-The simplest form of hot surface recycling is the heater-planer. This device has been in use for 20-25 years. The normal 
scope of operations involves heating and removing the top $3 / 4$ in layer of asphalt pavement by a planing action. This process is normally accomplished in advance of a new overlay. This method is particularly good for maintaining cross-slopes and curb reveals, correcting surface irregularities, correcting and eliminating skid resistance problems and promoting a good bond between the new overlay and the existing pavement.

Hot Milling-This form of surface recycling deals with removal of pavement up to $5 \mathrm{in}$. in depth. This is accomplished through the use of milling teeth mounted on a rotating drum. The same benefits attributed to the heater-planer can also be claimed when using this process. This technique is particularly good in urban areas where large pavement buildups are encountered. The reclaimed hot material has been reused in low volume applications such as alleys and parking lots.

Heater-Scarifier-The most common form of hot surface recycling is the heater-scarifier. It is a process that is mainly used to correct surface oxidation problems. The normal scope of operations involve heating the surface, scarifying to a maximum depath of 1 in., adding a rejuvenating agent and/or new virgin hot mix, and recompacting. Besides the same benefits claimed by the previous two methods, heater-scarification has been shown to control reflection crack development, as long as the reflection cracks are not of a structural origin.

The major limitations associated with the heated process are in the area of energy consumption and emissions. In order to heat the surface, large amounts of fuel, normally propane or butane, are required. Some heater-scarifiers consume 20,000 BTU/SY scarified. Related to the pavement heating process, are the problems of killing roadside vegetation and smoking due to burning of the asphalt itself. The smoking problem can be controlled through the use of radiant emitters that indirectly heat the asphalt.

\section{Cold Process}

The other surface recycling category is the cold process. In this method the pavement surface is removed without additional heat. The equipment used in this type of reclaimation can remove material up to $5 \mathrm{in}$. in depth and $12 \mathrm{ft}$. in width in one pass. The process can be carried on in most any type of weather.

In its simplest form the cold process can be classified as cold planing. Cold planing is normally associated with the removal of a bituminous overlay from pavement. Removal can be accomplished through the use of a blade on a motor patrol, a tractor or a loader. 
The most popular form of surface recycling is cold milling. The equipment used in this method consists of cutting teeth mounted on a rotating mandrel that is attached to and driven by a prime mover unit. In its simplest form the mandrel is mounted on a grader or tractor frame. The more sophisticated machines are track-type units that can maintain precise grade and cross slope control. These machines are able to vary the gradation of the material removed by varying forward speed and cutting tooth arrangements. The resultant milled surface exhibits an excellent skid resistant pattern and promotes good bonding for subsequent overlays. The milled material has been widely recycled utilizing a variety of construction methods and equipment.

The major limitation of this type of recycling is the high initial machine cost and the cost of replacing the cutting teeth. The wear and life of the cutting teeth is a function of the aggregate in the asphalt being milled and the depth for which the pavement is being cut.

\section{CENTRAL PLANT RECYCLING}

The second major category of recycling is central plant. The basic operations involved in this method are removal of the pavement from the roadbed, crushing of the pavement to a predetermined maximum size, mixing with new aggregate and/or binder in a central plant, and reapplication to the roadbed. The removal of the pavement can be accomplished by ripping or milling. Crushing is either accomplished on the roadbed, using traveling hammermills or scarifiers, or the material may be crushed at a central location, commonly by the use of a jaw and/or a roll or cone crusher.

The major advantage of central plant recycling is the high degree of quality control that can be maintained. Mix deficiencies may be readily corrected. Binder and aggregate proportions may be exactly controlled. Once it leaves the plant the material acts very similar to a new virgin mix.

The major problem that has been associated with central plant recycling has been the inability to use conventional asphalt plants to recycle. When the fine asphalt particles that exist in reclaimed pavements are exposed to open flames and temperatures in excess of $700^{\circ} \mathrm{F}$, emission control of the resulting smoke becomes a problem. The dryer on a conventional plant poses such a problem because the hot spot in the flame of the dryer can approach $2500^{\circ} \mathrm{F}$.

Several different solutions have been tried to alleviate the emission problem. The first attempt was the use of indirect heating utilizing heat exchange tubes. Robert Mendehall of RMI modified a conventional 
dryer by incorporating flame-carrying tubes in the drum, thus eliminating contact of the asphalt with the flame. This method was successful in eliminating emission control problems. However, the major disadvantage was the reduction in the plant capacity from $500 \mathrm{TPH}$ to something less than $100 \mathrm{TPH}$.

Today, the major solutions to the central plant emission control problem may be classified into two major areas-those that use drum mixers and those that use batch plants.

\section{Drum Mixers}

Drum mixers have been modified to recycle asphalt and meet emission control standards. These modifications were mainly developed by the major equipment manufacturers.

Boeing-The initial Boeing Construction Company solution to the problem was the installation of a ceramic grid heat shield in front of the flame to take care of the hot spot. This method was later refined by adding an enclosure around the flame, moving the burner back out of the drum and introducing additional cooling air (Fig. 8). This method has proved successful in controlling emissions, particularly when approximately $20 \%$ virgin aggregate

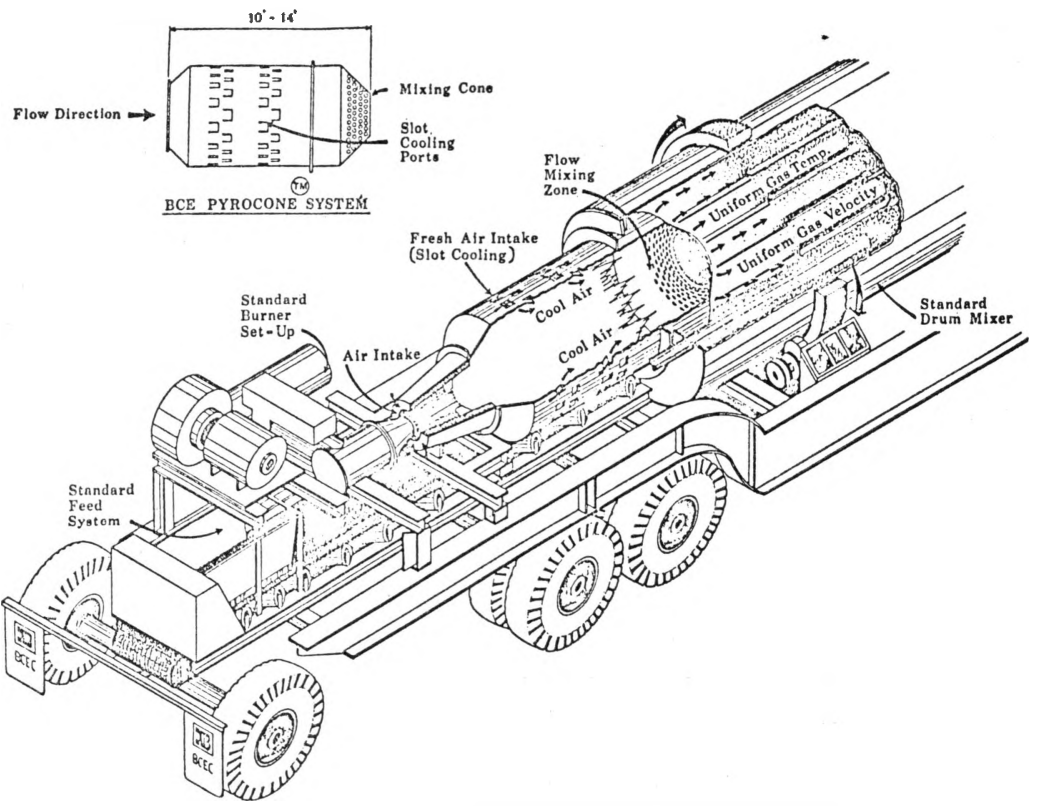

Figure 8. Boeing Drum Mix System (Boeing Construction Equipment Co.) 
is added to the reclaimed material. The major limitation of this solution is the inability to easily convert from recycled mixes to conventional mixes.

Cedarapids-The Iowa Manufacturing solution to the emission control problem was the addition of a small drum-64 in. diameter, inserted within a large diameter-110 in., conventional drum (Fig. 9). This method utilizes virgin aggregate which is superheated in the small drum. A "veil" of superheated virgin aggregate is created at the discharge end of this smaller drum and protects the reclaimed material from the burner flame. The reclaimed material is allowed to cascade over the small drum as it enters the large drum. The reclaimed material is heated by a heat exchange process that takes place between the new aggretgate and the reclaimed material, as well as between the outside of the small drum and the reclaimed material. Since no flame contacts the reclaimed asphalt, emissions problems are eliminated. The machine is capable of producing up to $500 \mathrm{TPH}$ and $80 / 20$ (80\% reclaimed-20\% virgin) mixes. However $50 / 50$ mixes are normal. The major

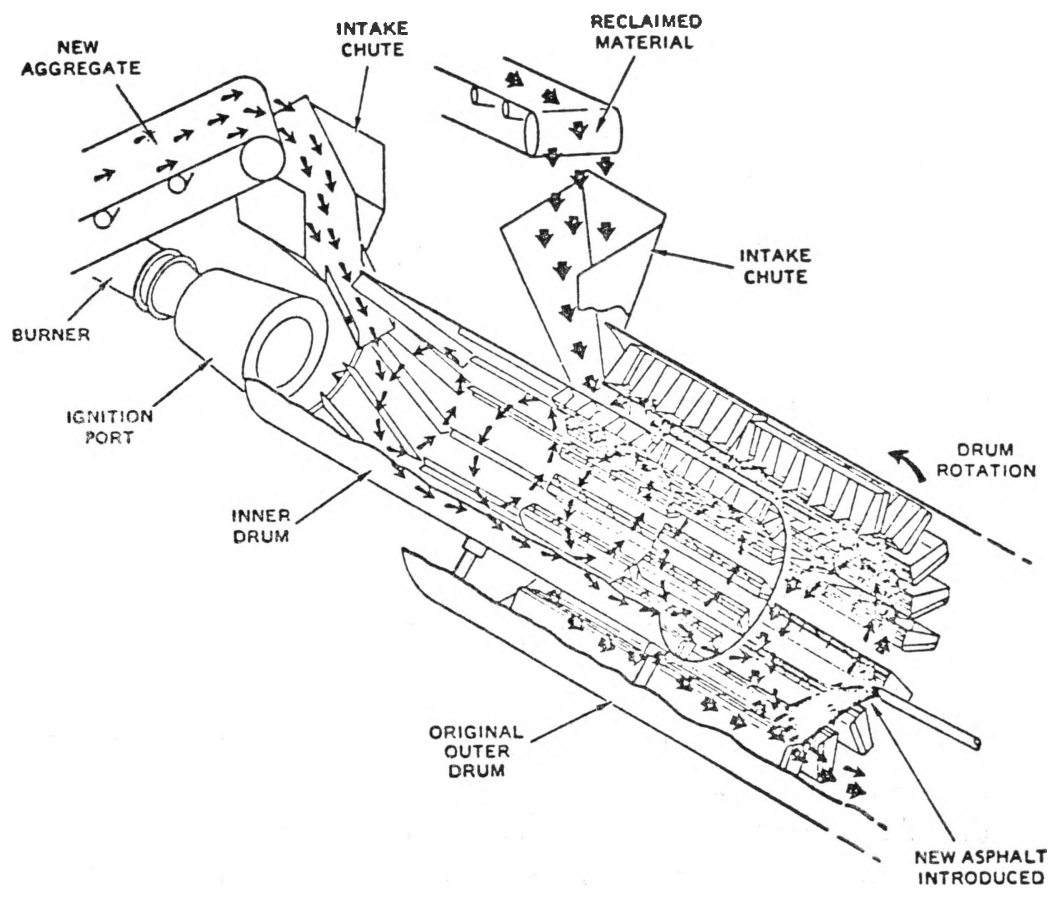

Figure 9. Cedarapids Drum-within-a-Drum Process (Iowa Manufacturing $\mathrm{C}_{0}$.). 
limitation of this process is the inability to readily switch from recycled to conventional mixes.

Barber Greene-The Barber Greene solution to the emission control problem is the use of a split stream entry into the drum. Virgin aggregate is entered into the drum at the normal point. The reclaimed material is added at the mid-point of the drum. Early attempts to add material at the midpoint utilized a rear-entry, slat conveyor (Fig. 10). However, bearing problems on the conveyor necessitated going to the use of rotary chutes at the drum mid-point

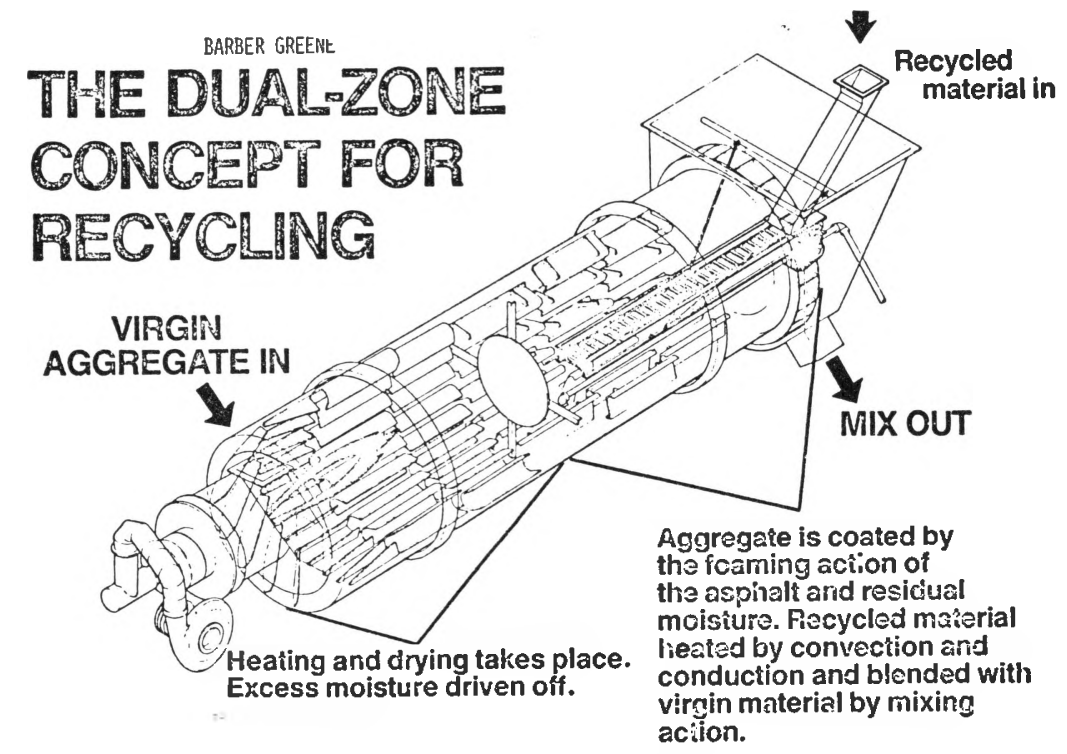

Figure 10. Rear Entry Conveyor on Barber Green Dual Zone System (Barber Greene Co.).

(Fig. 11). Production of this system is reported to be in excess of 300 TPH with mix composition of up to $70 / 30$ (reclaimed/virgin). A major advantage of the use of rotary chutes is the ease with which the system can be switched back and forth from recycling to conventional mixes.

CMI-The CMI solution to the emission control problem is also the use of split stream entry into the drum. CMI uses flop gates at the mid-point of the drum to allow entry of the reclaimed material (Fig. 12). Special flighting with specially designed slots are also utilized to create a protective veil between the burner and the reclaimed material. Production of this system is reported to be 450 


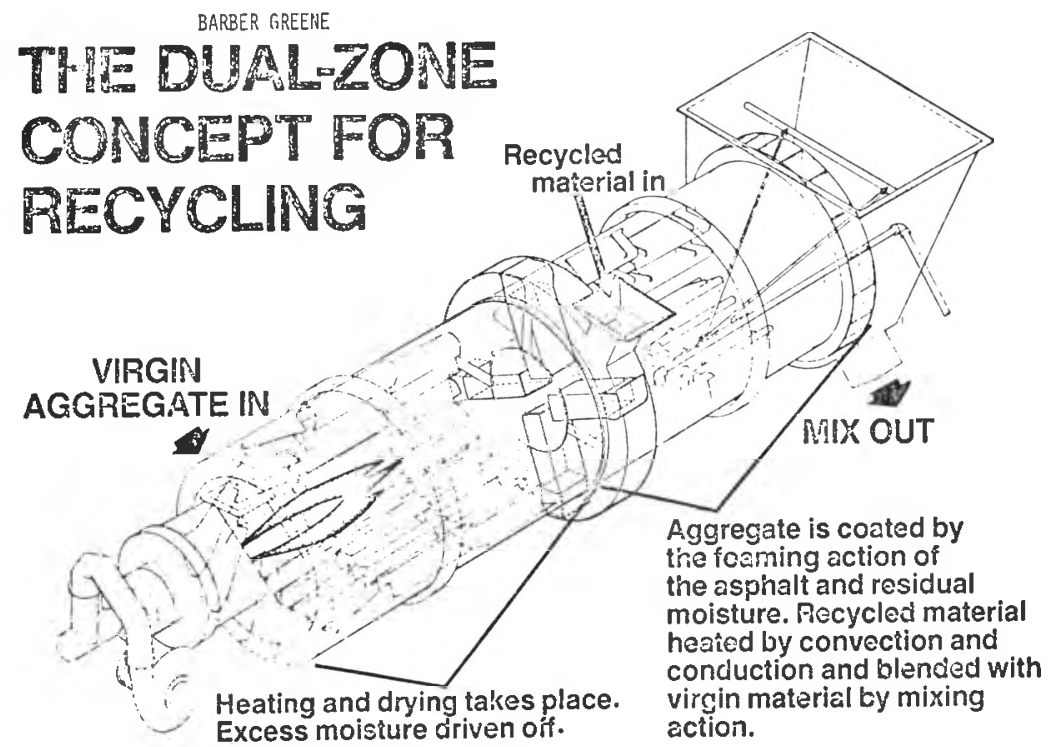

Figure 11. Rotary Chute Entry on Barber Green Dual Zone System (Barber Greene Co.).

TPH at mix compositions up to $70 / 30$ (reclaimed/virgin). Changeover from recycling to conventional is a simple matter of bolting the flop gates shut.

\section{Batch Plants}

The majority of the asphalt plants in this country are batch plants, not drum mixers. Development work has been done on utilizing these plants for recycling asphalt.

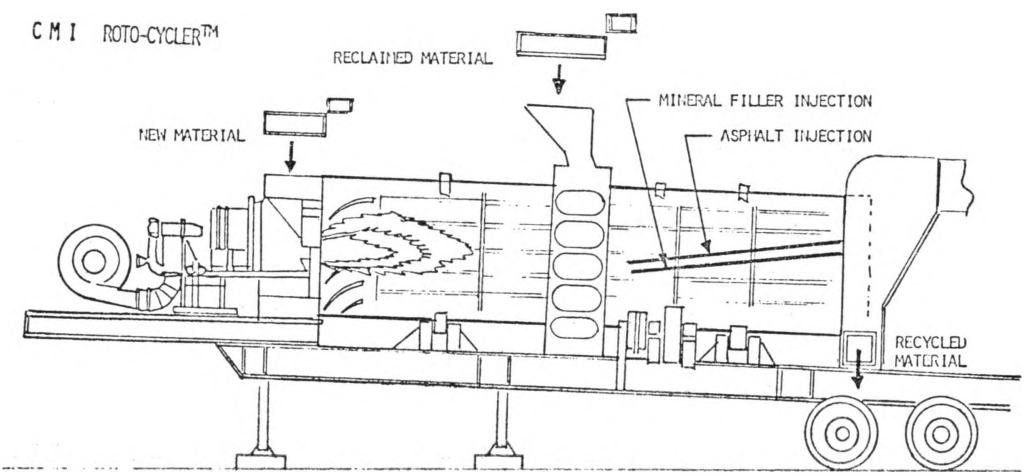

Figure 12. Mid-Point Flop Gate Entry on CMI Roto-Cycler (CMI Corp.). 


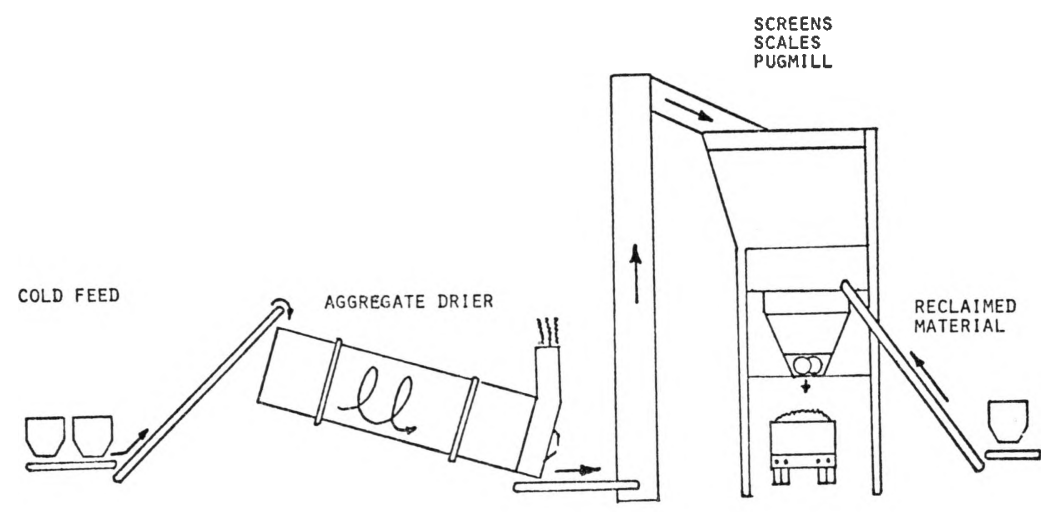

"MAPLEWOOD" HEAT TRAISSFER PROCESS

Figure 13. Heat Transfer Process Using a Conventional Batch Plant.

Maplewood-The first successful application of recycling through a batch plant was accomplished in the Minneapolis-St. Paul suburb of Maplewood. A batch plant was modified so that reclaimed material could be introduced into the weigh hopper, just above the pugmill (Fig. 13). Virgin aggregate, superheated to $450-500^{\circ} \mathrm{F}$ through a conventional dryer, is added to reclaimed material at the weigh hopper. A heat transfer process in the weigh hopper and in the pugmill heats the reclaimed material to the required mixing temperature. Pugmill mixing times were lengthened to 60 seconds. Recycled mixes were made using $50 \%$ reclaimed material and 50\% virgin aggregate, although 65/35 mixes are feasible. Discharge temperature of the recycled mixes are in the range of $215-240^{\circ} \mathrm{F}$.

Others-Other methods have been evaluated to utilize batch plants. One method uses two drum dryers. Virgin aggregate is superheated in the first dryer, while reclaimed material is heated to a low temperature in the second dryer (Fig. 14). Another method introduces the reclaimed material at the discharge end of the dryer and allows the heat transfer process to start in the hot elevator, prior to entering the hot storage bins and the weigh hopper.

\section{IN-PLACE RECYCLING}

The third major category of recycling is in-place recycling. In this method all work is accomplished on the roadbed, eliminating the need to transport material to a central location for processing. Normally this 


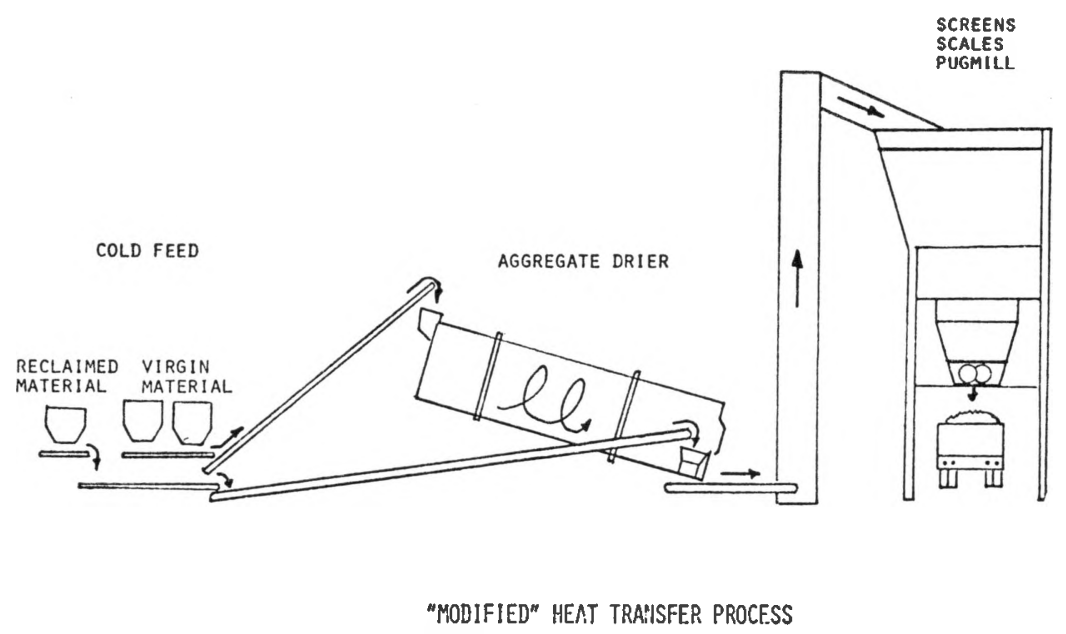

Figure 14. Heat Transfer Process Using a Conventional Batch Plant.

form of recycling utilizes common types of machines that are readily available to most contractors. The final product of this form of recycling is mostly used as improved or stabilized bases. Normally, a new overlay or surface treatment is used as a wearing surface. This method is particularly good for correcting or improving structural capacity and defects in the road. The major limitation of this process appears to be in the area of quality control of the end product. It is much more difficult to achieve uniform end results using this method as compared to central plant recycling.

There are a wide variety of methods and equipment that may be used to recycle in-place. Two methods that will be discussed are those used on projects in Michigan and Indiana.

\section{Michigan}

Thirty miles of $\mathrm{I}-75$ in the northern portion of the lower penninsula of Michigan have been recycled in-place over the past two years. The existing pavement consists of $4 \frac{1}{2}$ in. of plant mix asphalt concrete over 11 in. of gravel base and 25 in. of sand subbase. The pavement had deteriorated to a present serviceability index (PSI) of 1.05. Michigan utilizes a PSI of 2.5 as a minimum rating, below which the pavement must be rehabilitated.

The Michigan DOT chose to recycle the existing pavement in-place and to overlay it with new hot mix. The initial pavement removal process consisted of milling the top $2 \frac{1}{2} 2$ in. of pavement using a CMI 750 and a CMI 575 Rotomill, working in echelon. The remaining 
2 in. of pavement was scarified by using a Pettibone 660 hammermill. The pavement was reduced in size to a maximum of 2 in. A motor patrol worked the crushed pavement laterally across the roadbed to insure homogeneity and adequate material for cross-slope balance.

Additional water was added to the crushed pavement at the rate of $4-7 \%$. The purpose of the water was to aid in the mixing process by causing the material to fluff up. Mixing of the reclaimed pavement, $2 \mathrm{I} / 2$ to $3 \mathrm{in}$. of base aggregate and $1.3 \mathrm{gal} / \mathrm{sy}$ of $120-150$ penetration grade paving asphalt was accomplished by using two $\mathrm{P} \& \mathrm{H}$ Single Pass Stabilizers, working in echelon. The asphalt was piped to the stabilizer directly out of the transport tanker, at a temperature of $370-385^{\circ} \mathrm{F}$.

Initial compaction of the mix was accomplished with a sheepsfoot roller. Initial grading and balancing of the cross-section was accomplished with a motor patrol. A vibrating steel-wheeled roller followed. Final grading was accomplished with an electronically controlled grader blade that trimmed the stabilized base to the proper lateral and longitudinal elevation. Final compaction was achieved by the use of another vibratory roller. This recycled base was overlayed with a $130 \mathrm{lb} / \mathrm{sy}$ levelling course and a $120 \mathrm{lb} / \mathrm{sy}$ wearing course; yielding a $2 \frac{\mathrm{T}}{4} \mathrm{in}$. new wearing surface.

\section{Indiana}

3.7 miles of SR 32 in Fountain County Indiana was recycled in place during 1978. SR 32 is a low volume road that was a state highway takeover from the county. When the state assumed control in 1940 it was a gravel road. Through staged-construction the road received many different surface treatments and paving operations over the years. Recycling was chosen as a method to rehabilitate the pavement and upgrade the structural capacity of the road.

The initial recycling operation involved ripping the pavement by using three ripper teeth mounted on a motor grader. Scarification was achieved through the use of a Bros and a Ray-Go Soil Stabilizer, cutting $4 \mathrm{~T} / 4$ in. deep, to yield 2 in. maximum size material in three passes. Material was shaped with a motor patrol and recompacted to allow local traffic back on the road.

Since SR 32 was a stage-constructed road, the scarified bituminous mix exhibited a definite lack of large coarse aggregate. To correct this deficiency, $1 \mathrm{~T} / 2$ in. of \#4's were added in two lifts. An emulsion, AE 150, was applied, cold, with a distributor at the rate of $1-1.4 \%$. After allowing for penetration, the material was once again ripped using the 
grader ripper and mixed, using the Ray-Go stabilizer, to a depth of 6 in. The recycled material was leveled with a motor patrol and compacted with a vibratory roller. This improved base was then overlayed with 2 in. of a $\# 53$ dense-graded hot mix followed by a chip and seal surace treatment.

\section{RESEARCH}

It is in the last area of recycling, in-place, that we at Purdue have concentrated our research effort. Mang Tia has conducted an investigation of cold, in-place recycled mixes. The objectives of his study were:

1. To evaluate the effect of the following on cold, recycled mixes:

A. Amount and type of binders added

B. Amount of moisture added in the mixing process

C. Amount of virgin aggregate added

D. Compactive effort

E. Curing time

2. To determine the suitability of cold, recycled asphalt mixes, stabilized bases, or surface courses.

3. To develope guidelines for the design of cold-mix recycled pavements.

Pavement samples used in this laboratory study were obtained from SR 32 and crushed in a jaw crusher. Binders investigated were AC 200 (AP-O), MC 3000, AE 90 and AE 150. The gyratory compactor was used to fabricate 4 in. diameter by $21 / 2$ in. specimens.

The major findings of the study were:

1. The gyratory compactor proved to be a valuable tool in evaluating long-term performance of recycled mixes and identifying mixture instability.

2. Excessive binder content was the major cause of instability of recycled mixes.

3. The binders displayed different rejuvenating effect. In order of least to most rejuvenation, the binders investigated are ranked as follows: AC-200, MC 3000, $\mathrm{AE} 90$ and $\mathrm{AE} 150$.

4. The binders displayed different water resistance abilities. A ranking of least resistance to meet resistance yields: $\mathrm{AE} \mathrm{90,}$ MC 3000, AE 150 and AC 200.

Future work is proposed for the laboratory investigation of cold, recycling mixes. Areas to be investigated are: 
1. Mix design using the gyratory compactor.

2. The long-term rejuvenating effects of various binders and rejuvenating agents.

3. Use of foamed asphalt.

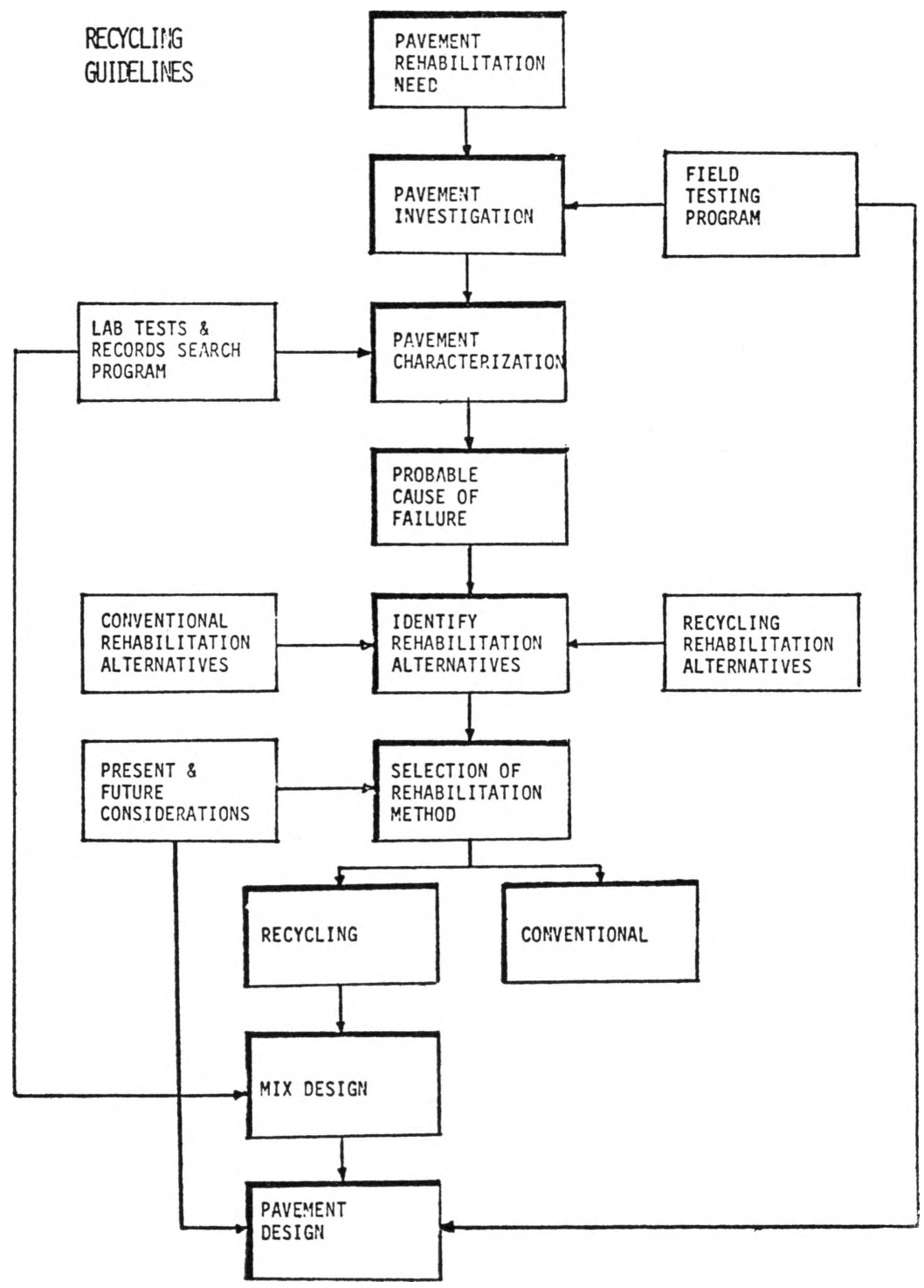

Figure 15. Recycling Guidelines. 


\section{In-Place Study}

The second major area of research has concentrated on the investigation of in-place recycling. One of the major tasks is the development of guidelines to assist the pavement engineer in the selection of pavements that can be recycled by the cold, in-place process. Figure 15 is an illustration of a flow chart of these guidelines. Once a pavement is selected as a possible candidate, a field testing program would be initiated (Fig. 16). The program would check: the road adequacy by

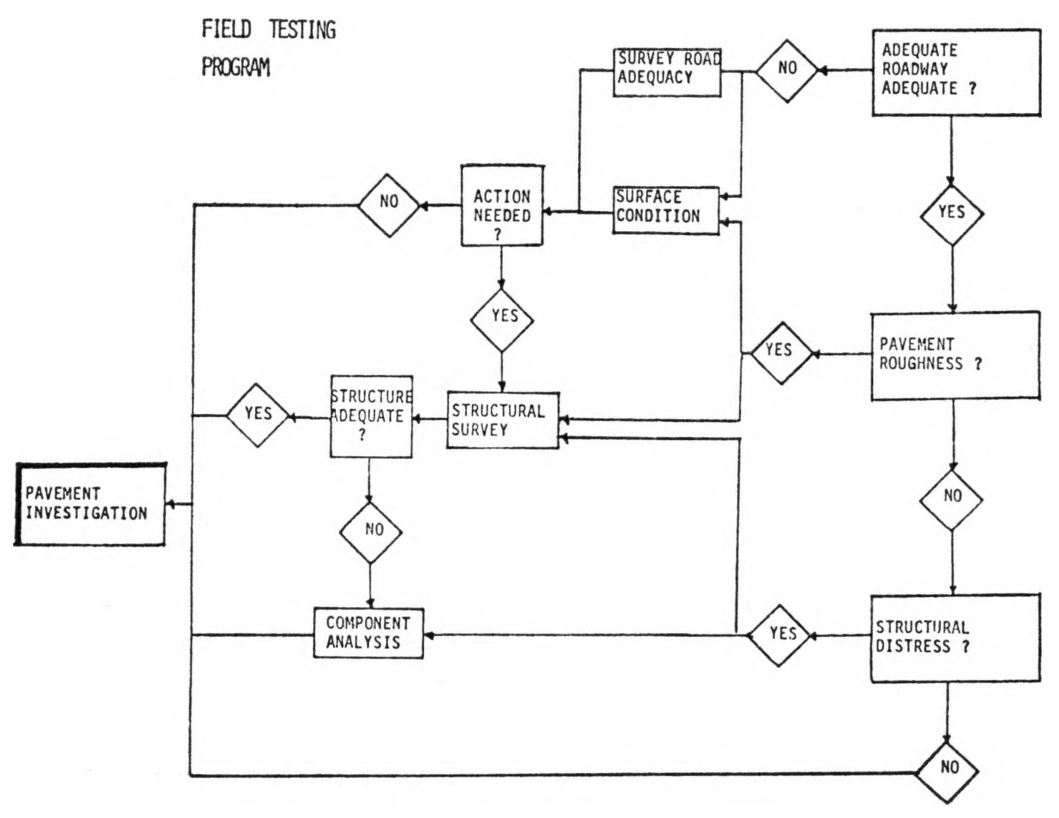

Figure 16. Field Testing Program.

comparing the existing road with standards for geometry and alignment; the surface condition by using either a present service rating or a present serviceability index; the structural condition by surveying structural distress; and conducting a component analysis or Dynaflect Survey of the pavement structure.

The next step would be to compare the results of a laboratory testing program on cores extracted from the road with the findings from a search of design, construction and maintenance records (Fig. 17). Pavement variability would be evaluated and additional sampling could be indicated. 


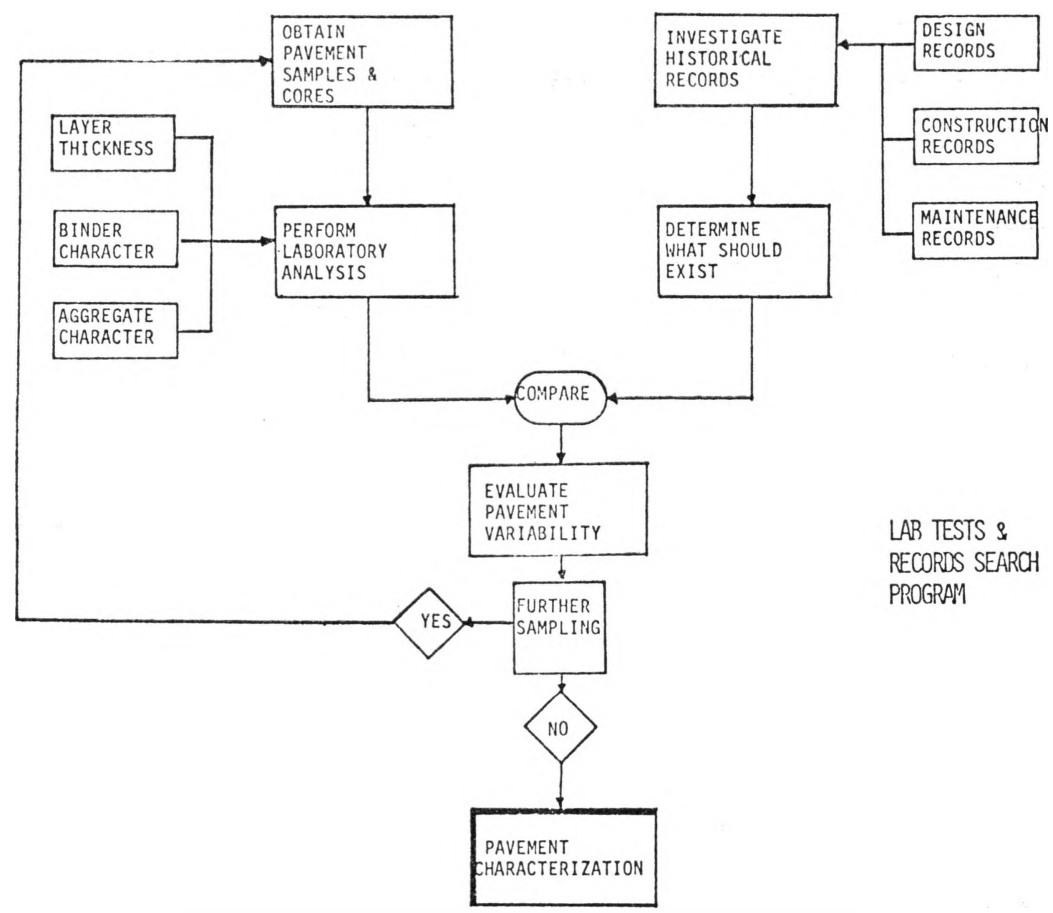

Figure 17. Lab Tests and Records Search Program.

Utilizing the previous information, a probable cause of failure would be determined. For the failure mode indicated, conventional rehabilitation alternatives would be formulated and recycling rehabilitation alter-

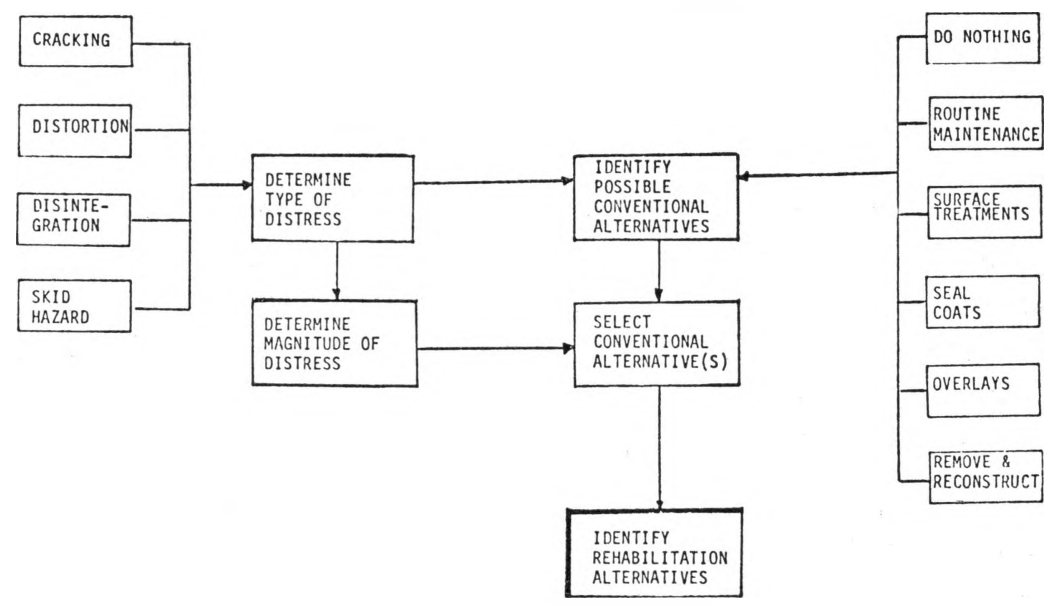

Figure 18. Conventional Rehabilitation Alternatives. 
natives selected (Fig. 18, 19). Incorporating these factors with present and future consideration, a rehabilitation method would be selected. If recycling, particularly in-place recycling is chosen, the guidelines would assist in mix design as well as pavement design.

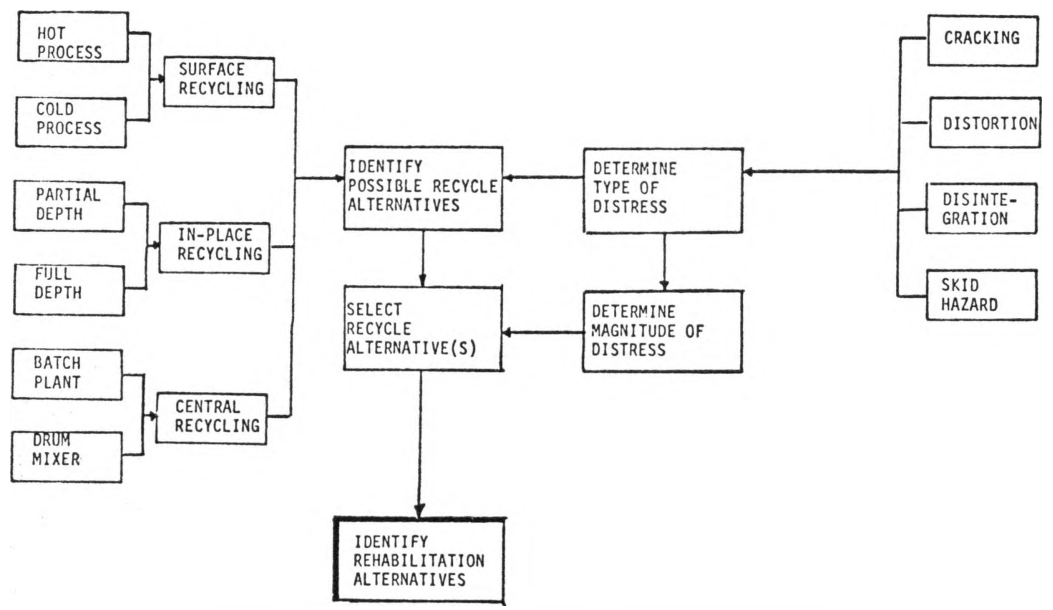

Figure 19. Recycling Rehabilitation Alternatives.

The next process would be the selection of a specific construction system. Equipment and methods would be selected on a basis of economics and energy considerations. Model specifications for construction would be developed and quality control measures be outlined for the exact method chosen. Work is continuing in this area.

\section{CONCLUSION}

Recycling has come of age. Recycling of bituminous pavements will, if not already, provide the pavement engineer with a viable alternate to maintain and rehabilitate asphalt roads. 